\title{
Effects of a school based exercise program on children's resistance and flexibility
}

\author{
RFC Moreira ${ }^{\mathrm{a}}$, FH Akagi ${ }^{\mathrm{a}}$, PYL Wun ${ }^{\mathrm{a}}$, CS Moriguchi ${ }^{\mathrm{a}}$ and TO Sato ${ }^{\mathrm{a},{ }^{*}}$ \\ ${ }^{a}$ Physical Therapy Department, Federal University of São Carlos, Rodovia Washington Luis, Km 235. Zip Code \\ 13565-905, São Carlos, São Paulo, Brazil
}

\begin{abstract}
The aim of this study was to evaluate the short term effects of an exercise program on abdominal and back muscles resistance and hamstring flexibility among schoolchildren. Fifty eight healthy schoolchildren were divided into two groups: experimental (15 males and 14 females; mean age $12.2 \pm 1.8$ years) and control (14 males and 15 females; mean age $11.9 \pm 2.1$ years). The intervention was performed twice a week, on nonconsecutive days, during six weeks. The duration of each session was fifty minutes and they were composed by warming up aerobic exercises, isotonic and isometric abdominal and back muscle exercises and hamstring stretching. The intervention effects were evaluated through Kraus-Weber test (abdominal resistance), modified Biering-Sørensen test (back muscle resistance) and sit and reach test (hamstring flexibility). Data were analyzed by mixed-design two-way ANOVA, with one between-subjects and one within-subject (time) factors. The alpha level was set at $\mathrm{P} \leq 0.05$. The experimental group improved back muscles resistance and hamstring flexibility, but not abdominal muscles resistance. There was a significant interaction between groups and time for back muscles resistance $(\mathrm{P}=0.018)$ and for hamstring flexibility $(\mathrm{P}=0.017)$. The 6 -week training period showed positive results in improving back muscles resistance and hamstring flexibility of schoolchildren.
\end{abstract}

Keywords: early prevention, intervention, back pain, student

\section{Introduction}

Epidemiological studies have identified a high prevalence of low back pain in school-age children $[6,8,12,19]$. It is believed that low back pain during childhood represents a predisposing factor for future low back symptoms in adulthood [5], besides its impact on daily living activities and social functioning $[12,13]$.

Low back pain among children and adolescents has a multifactorial etiology [18], which is associated to personal factors and lifestyle such as overweight, flexibility, muscle strength, eating habits, smoking, alcohol consumption, physical activity level, participation in sports and work activities [7,18].

Low back stability and hamstrings flexibility have being demonstrated to be associated with low back pain occurrence in this population $[14,15]$. Considering that, exercise training programs that focus on low back stability and mobility through strength and stretching exercises would be a possible intervention strategy for preventing low back pain in schoolchild- ren $[9,11,17,18]$. However, it is necessary to evaluate if exercise training is efficient in promoting muscle endurance and flexibility improvements.

Positive results would allow and lead to the implementation of this kind of program as a low back pain prevention strategy. So, the main goal of this study was to evaluate the effects of a physical training program based on resisted and stretching exercises on school-age children muscle resistance, focusing on back extensors and abdominal muscles, as well as on hamstrings muscle flexibility.

\section{Materials and methods}

\subsection{Participants}

All pupils from $4^{\text {th }}$ to $8^{\text {th }}$ grade from a Brazilian state school were invited to take part in the study. The inclusion criteria to consider students eligible to participate in the study were: 1 . Present a standard informed consent form signed by parents, allowing the child to take part in the study; 2 . To be physically

*Corresponding author. E-mail: tatisato@gmail.com. Tel. number +55(16)3351-9576. Fax number: +55(16)3361-2081. 
fit to participate in the evaluation and intervention procedures; 3. Do not present any musculoskeletal system alteration as well as any neurologic, cardiologic, metabolic or rheumatic disease.

Eighty students brought the consent form signed and were randomly allocated to the experimental and control group. Thirty-five participants were assigned to the experimental group and forty-five to the control group. Those students who were absent during the evaluation step, as well as those ones who were not able to finish the muscle resistance training, were excluded from the study $(\mathrm{n}=22)$. The final sample was composed by 58 participants. Main characteristics of both groups participants are shown in Table 1.

This study was in accordance with the Brazilian National Health Council Resolution 196/96 on ethical issues and was approved by the Ethics Committee of the Federal University of São Carlos (CAAE - Application Certificate for Ethical Appreciation 0124.0.135.000-08, opinion No. 039/2009).

Table 1. Groups characteristics.

\begin{tabular}{llcc}
\hline Characteristic & & Group & \\
& & Control (n=30) & Experimental (n=28) \\
\hline Age (year) & male & $11.9 \pm 2.1$ & $12.2 \pm 1.8$ \\
Gender & female & 15 & 15 \\
& & 15 & 13 \\
Weight (kg) & & $46.41 \pm 15.2$ & $59.63 \pm 14$ \\
Height (m) & $1.48 \pm 0.11$ & $1.57 \pm 0.12$ \\
\hline
\end{tabular}

\subsection{Procedures}

All the participants were evaluated before and after the intervention period which lasted 6 weeks. The evaluations were performed during the regular class period in a private room.

\subsubsection{Flexibility and Resistance Assessment}

First, students were weighed and measured using a digital balance $\left(\right.$ Mallory $\left.{ }^{\circledR}\right)$ and also a meter tape, respectively. In the next step, age, grade, hand and foot laterality were recorded.

After these data collections, flexibility and resistance tests were conducted. Before each test, a fami liarization time was performed during short periods to avoid muscle fatigue. Three trials of each test were recorded, but only maximal values were used for data analysis.

\subsubsection{Flexibility test}

Hamstring and lower back flexibility were evaluated throughout sit and reach test (Figure 1) described by Wells and Dillon [20]. Flexibility measure corresponded to the difference between the value in the initial position and the maximal value reached during the test.
During that test, the student was sitting with extended knees, hip flexion of $90^{\circ}$ and feet leaning parallel to the apparatus surface. Shoulders flexion was required to determine the initial position of the test, as we can see in Figure 1. Then the students were instructed to breath in, and to flex the hip and the back toward the apparatus while breathing out, pulling the rule as much as they were able to, without flexing the knees.

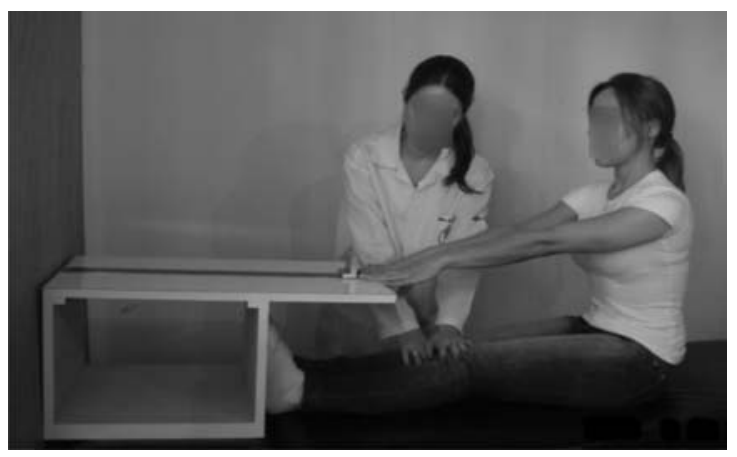

Fig. 1. Sit and reach test.

\subsubsection{Resistance test}

Tests of abdominal and trunk extensor muscles resistance were performed in a random order. Resis- 
tance was estimated by means of the maximal time maintaining isometric muscle contraction. Abdominal resistance was evaluated through Kraus-Webber test. The student had to lay on a flat surface with knees and hip flexed and arms crossed above the chest (Figure 2). Then the students were instructed to flex the trunk until the scapular inferior angle leaves the surface and to hold that position. The end of the test was determined when the scapular inferior angle touched the finger of the therapist positioned above the surface.

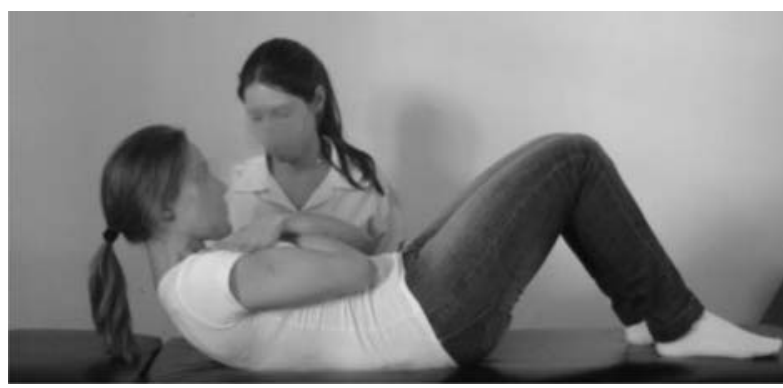

Figure 2. Abdominal muscles resistance test.

Back extensor muscles resistance was evaluated by Biering-Sorensen test [10]. The student laid on a flat surface in prone position and $\mathrm{s} /$ he was attached to the surface using tapes and by the therapist (Figure 3). The anterior superior iliac spine was used as reference to position the student on the surface. Then, the students were instructed to maintain the extension of the back. The end of the test was determined when the student laid down the upper arms under the surface level.

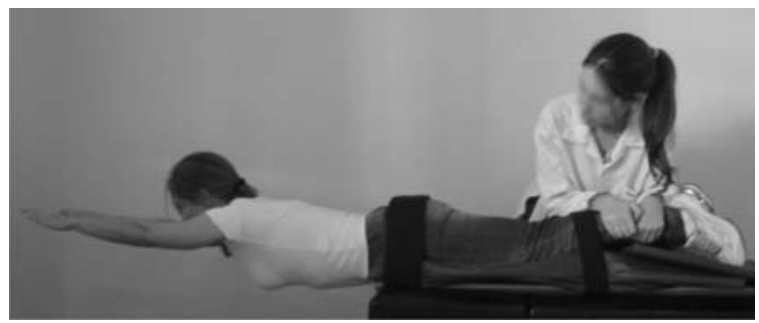

Fig. 3. Back extensor resistance test.

\subsubsection{Intervention Program}

Student group under intervention (experimental group) performed an exercise program during 6 weeks after school classes. The training was performed twice a week on non-consecutive days (total of 12 exercise training days). Each training session lasted 60 minutes.

The first 10 minutes were composed by running games for warming up (Figure 4A). In the next step, exercises focusing on low back stability were performed: curl-up (Figure 4B), curl-up oblique variation (Figure 4C), bridge (4D), birddog (Figure 4E), bridge from the knees (4F), back extension (4G); and spine mobility by cat-camel $(4 \mathrm{H})$. Three series, composed of 15 to 20 repetitions each, were performed of curl-up exercises and cat-camel. Other exercises were performed in 3 trials of 20 to 30 seconds of isometric contraction. The program ended with stretching exercises of hamstrings (4I) during 30 seconds. 

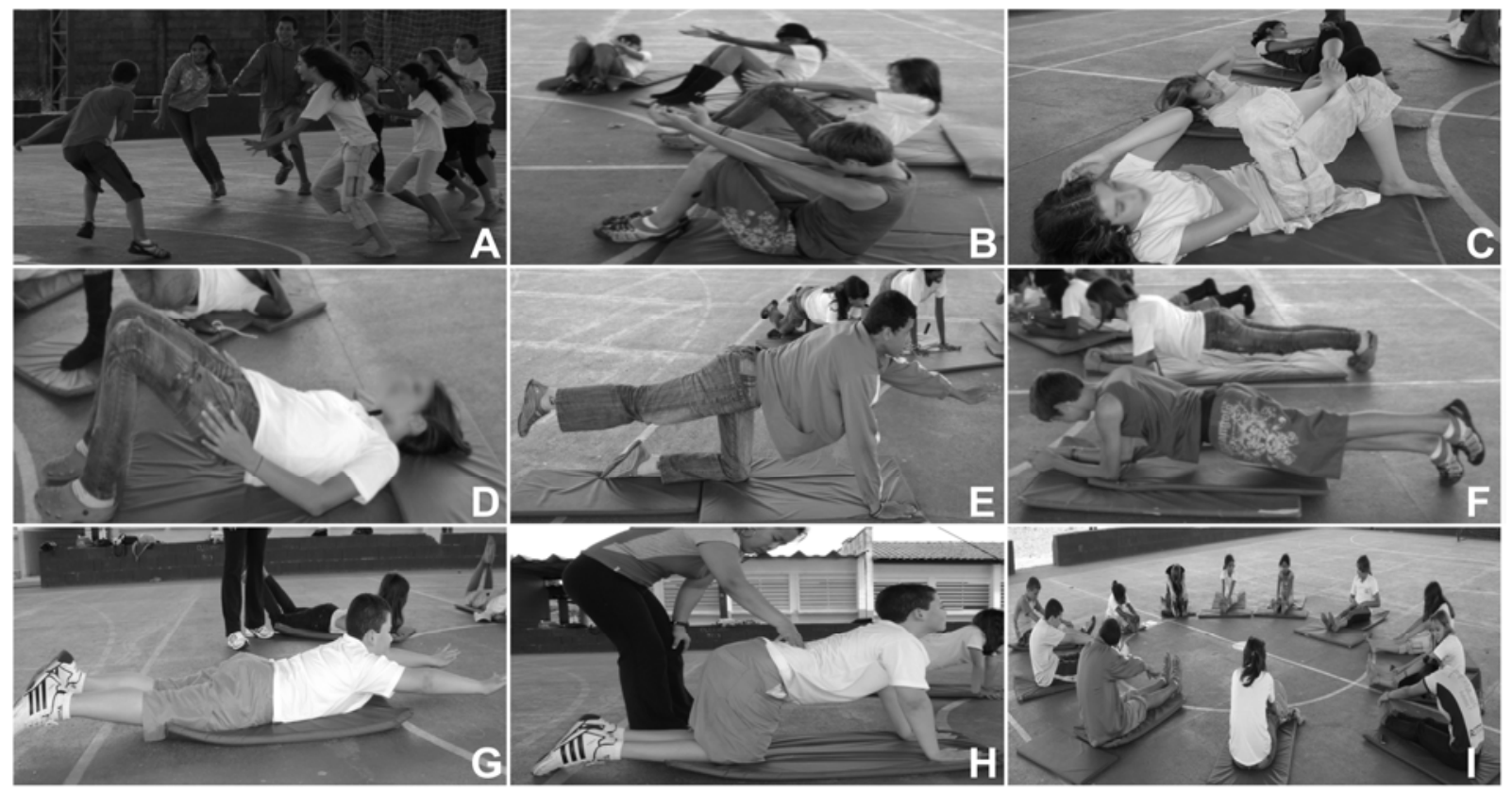

Fig. 4. Training exercises. A. Warming up exercises. B. Curl-up. C. Curl-up oblique variation. D. Bridge. E. Bird dog. F. Bridge from the knees. G. Back extension. H. Spine mobility by cat-camel.

\subsection{Data analysis}

Experimental and control groups were compared regarding age, weight and height using t-Student test for independent samples, since the data presented normal distribution. Resistance and flexibility were analyzed by mixed design Analysis of Variance (ANOVA), since data have shown variance homogeneity and normal distribution. For ANOVA analysis, groups were considered as independent variable (between-subjects factor) and the before and after intervention measurements of flexibility and resistance as repeated measured (within subject factor). The level of significance was set at 5\% $(P \leq 0.05)$. All analyses were performed using SPSS 11.5.

\section{Results}

Control and experimental groups did not differ regarding age $(\mathrm{p}=0.58)$ or body weight $(\mathrm{p}=0.40)$ but it was identified a significant difference for height $(\mathrm{p}=0.006)$.

It is possible to identify that both groups improved abdominal muscular resistance and hamstrings flexibility after the intervention period. For back extensors resistance, the control group presented a reduction while the experimental group presented high values related to the back muscles resistance (Table 2).

Table 2. Mean and standard deviation of the abdominal and back extensor resistance tests and hamstring flexibility pre- and postintervention in experimental and control groups.

\begin{tabular}{|c|c|c|c|c|c|c|}
\hline & \multicolumn{4}{|c|}{ Group } & \multirow{2}{*}{\multicolumn{2}{|c|}{ Total sample $(n=58)$}} \\
\hline & \multicolumn{2}{|c|}{ Control $(n=30)$} & \multicolumn{2}{|c|}{ Experimental $(n=28)$} & & \\
\hline & pre & post & pre & post & pre & post \\
\hline \multicolumn{7}{|c|}{ Abdominal resistance (s) } \\
\hline mean & 24.5 & 24.9 & 28.6 & 31.0 & 26.4 & 27.8 \\
\hline standard deviation & 17.8 & 13.9 & 12.6 & 15.2 & 15.5 & 14.7 \\
\hline minimum & 0.0 & 0.0 & 9.0 & 12.0 & 0.0 & 0.0 \\
\hline
\end{tabular}




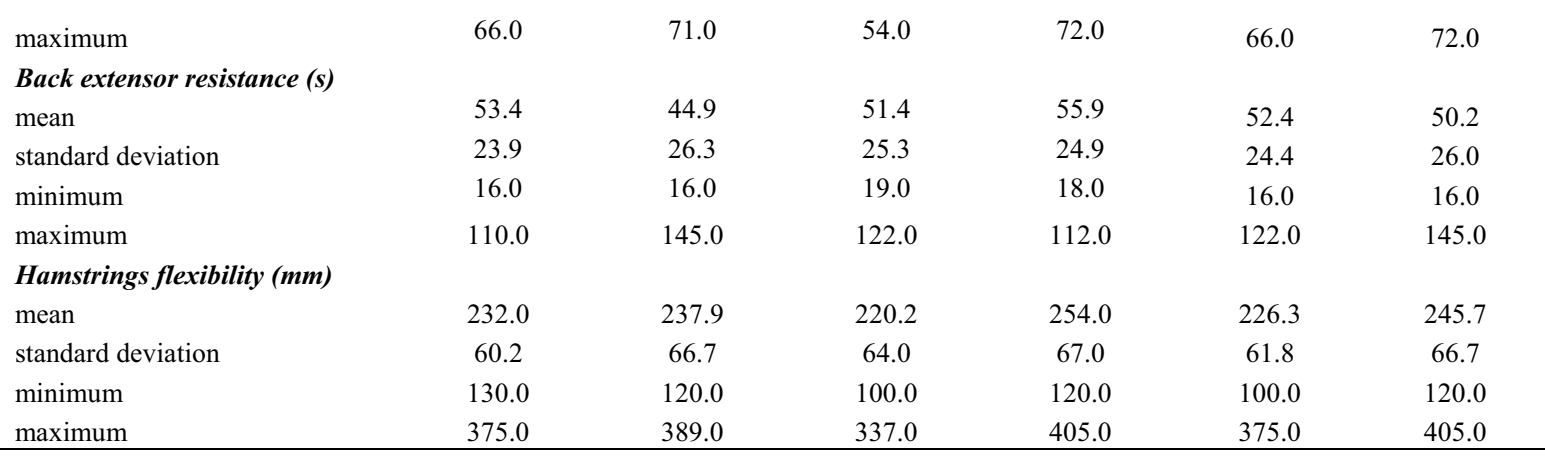

The variance analysis identified interaction between the factors group and time for back extensors muscle resistance $(\mathrm{p}=0.018)$ and for hamstring flexibility $(P=0.017)$, as it is shown in Figure 5 .
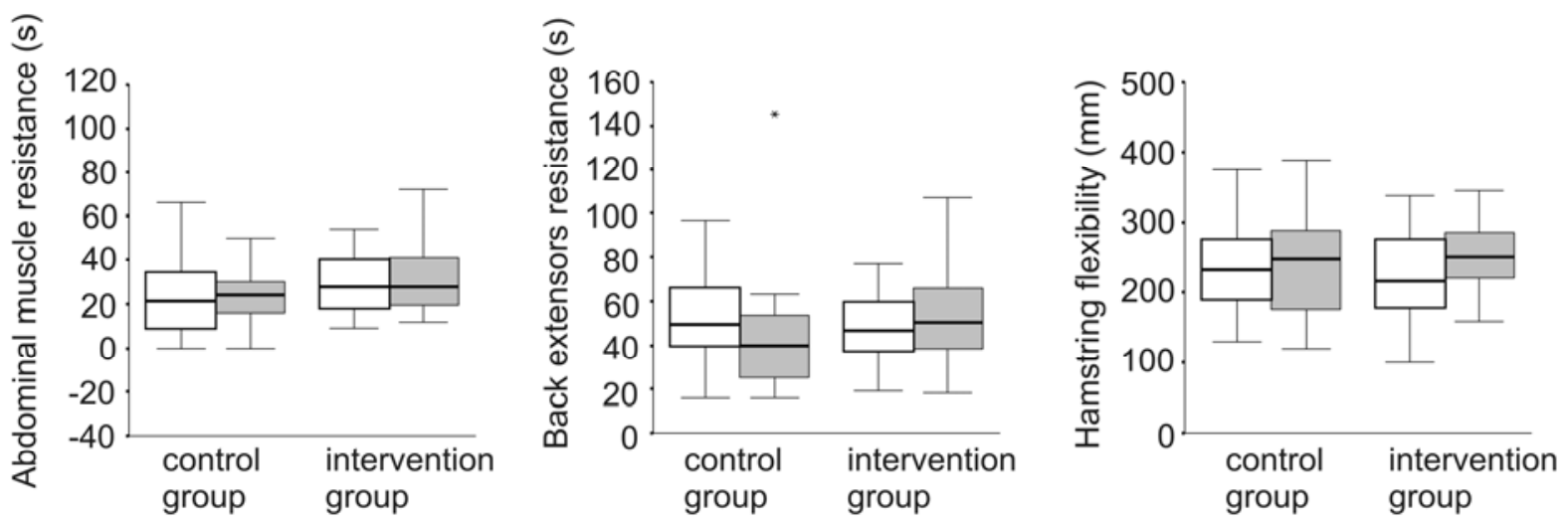

Fig. 5. Abdominal and back extensors muscles maximum resistance values and hamstring flexibility for control and intervention groups in pre (white) and post (gray) intervention periods. (*) indicates an extreme value.

\section{Discussion}

The exercises applied during the program sessions followed the guidelines and recommendations for children resistance training [2,3] and focused on lumbar stability as a protective measure for the vertebral column. According to McGill [9], lumbar stability or "core stability" could be achieved through low back mobility exercises and resistance exercises of the paraspinal and abdominal muscles. This author reported that low back instability is not related to insufficient muscle strength but rather to insufficient resistance. Stretching exercises are important to improve low back mobility patterns which help in low back pain prevention [11].
The exercise program applied resulted in improvement of back extensors muscle resistance. These results were expected as physical training programs shows positive results related to muscle resistance in children, especially when the training programs are associated with high number of repetitions and moderate loads [4]. The lack of muscle resistance improvement for the abdominal muscles could be attributed to the low number of exercises in the program specifically designed to these muscles, when compared to the number of exercises that focused on back muscles resistance. Besides that, another fact that should be considered is the students' difficulty on correctly performing the abdominal exercises as it requires trunk elevation against gravidity which is associated with a high level of exertion. Frequently, the students performed neck flexion associated with 
an insufficient trunk elevation, even under constant supervision and advisement.

The exercise specificity is another factor that could have jeopardized the results related to abdominal muscle resistance. The training proposed included abdominal exercises associated with isotonic contractions through trunk flexion repetition against gravidity. Nevertheless, during the evaluation procedure, these muscles were tested in isometric contraction. Considering response specificity to the applied stimulus, the abdominal muscular evaluation should have prioritized isotonic contractions instead of an isometric test.

On the other hand, the exercises performed for back muscles were mainly based on isometric contractions in accordance with the type of contraction tested in the evaluation through the Biering-Sorensen test. According to Moreau et al. [10], the BieringSorensen is a valid test that provides a global measurement of back extension endurance capacity besides presenting good result reproducibility. However, the influence of motivational factors during the test procedure must be considered [10].

The program also showed positive findings regarding hamstring flexibility. Thus, the inclusion of stretching exercises for schoolchildren could bring benefits for this population, as they could present a reduced flexibility due to the rapid growth of long bones [1]. Regarding low back pain prevention, the stretching exercises are important as they improve back mobility [11] and posture [16].

The height difference between groups could interfere on results as height is a factor negatively associated to the back extensor resistance test [10]. However, it was applied a variance analysis to identify between factors interaction, and as students height is a factor that do not show large changes in a period of six weeks, so the influence of this variable on the results could be disregarded.

Different from previous studies, resistance training programs can be considered safe when adequately supervised. One of the warnings related to this kind of training is the epiphyseal plates injury. However, this kind of injury mainly occurs at maximal loads conditions, when the exercises are incorrectly performed and/or in the absence of an adequate supervision [3]. In this study, the risk of injury were minimized as the sessions were accomplished under frequent and qualified supervision and the exercises were performed against gravidity without any kind of additional external load.

In addition to the possible benefits related to low back pain prevention, other benefits associated to the resistance training could be expected, as the improvement of motor ability, reduction of the risk of injuries during sports activities, children's weight control, improvement in bone mineral density besides the positive influences on psychological parameters and socialization $[2,3]$. The benefits related to resistance training performance during childhood can also be extended to adulthood through the change on physical activity practice and contribution for chronic diseases prevention [2,3].

\section{Conclusion}

The training program resulted in improvement of back extensors muscle resistance and hamstrings flexibility. On the other hand, the abdominal muscles exercises were not sufficient to promote improvement on muscle resistance. Nevertheless, new studies taking into account the training specificity are necessary to confirm these results. Six week training program for low back stability can be positive for schoolchildren besides promoting benefits for the general health. Future longitudinal studies are necessary to verify the efficacy of these programs for low back pain prevention on adulthood.

\section{References}

[1] M.J. Alter. Ciência da flexibilidade. ArtMed, Porto Alegre, 2001, pp. 365

[2] D.G. Behm, A.D. Faigenbaum, B. Falk, P. Klentrou. Canadian Society for Exercise Physiology position paper: resistance training in children and adolescents. Appl Physiol Nutr Metab 33 (2008), 547-561

[3] A.D. Faigenbaum, W.J. Kraemer, C.J.R. Blimkie, I. Jeffreys, L.J. Micheli, M. Nitka, T.W. Rowland. Youth resistance training: Updated position statement paper from the National Strenght and Conditioning Association. J Strength Cond Res 23 (2009), S60-S79.

[4] A.D. Faigenbaum, W.L. Westcott, R.L. Loud, C. Long. The effects of different resistance training protocols on muscular strength and endurance development in children. Pediatrics 104 (1999), 1-7.

[5] L. Hestbaek, C. Leboeuf-Yde, Kyvik KO, Manniche C. The course of low back pain from adolescence to adulthood. Eightyear follow up of 9600 twins. Spine 31 (2006), 468-472.

[6] L.J. Jeffries, S.F. Milanese, K.A. Grimmer-Somers. Epidemiology of adolescent spinal pain. A systematic overview of the research literature. Spine 32 (2007), 2630-2637.

[7] M.A. Jones, G. Stratton, T. Reilly, V.B. Unnithan. Biological risk indicators for recurrent non-specific low back pain in adolescents. Br J Sports Med 39 (2005), 137-140.

[8] S. Masiero, E. Carraro, A. Celia, D. Sarto, M. Ermani. Prevalence of nonspecific low back pain in schoolchildren aged between 13 and 15 years. ActaPaediatr 97 (2008), 212-216. 
[9] S.M. McGill. Low back stability: from formal description to issues for performance and rehabilitation. Exercise and Sport Sciences Reviews 29 (2001), 26-31.

[10]C.E. Moreau, B.N. Green, C.D. Johnson, S.R. Moreau. Isometric back extension endurance tests: a review of the literature. Journal of Manipulative and Physiological Therapeutics 24 (2001), 110-122.

[11] J. Rainville, C. Hartigan, E. Martinez, J. Limke, C. Jouve, M. Finno. Exercise as a treatment for chronic low back pain. The Spine Journal 4 (2004), 106-115.

[12] A. Roth-Isigkeit, U. Thyen, H. Stöven, J. Schwarzenberger, P. Schmucker. Pain among children and adolescents: restrictions in daily living and triggering factors. Pediatrics 115 (2005), e152-e162.

[13] T. Sato, T. Ito, T. Hirano, O. Morita, R. Kikuchi, N. Endo, N. Tanabe. Low back pain in childhood and adolescence: a crosssectional study in Niigata City. Eur Spine J 17 (2008), 14411447.

[14]A.N. Sjölie AN. Low-back pain in adolescents is associated with poor hip mobility and high body mass index. Scand $\mathrm{J}$ Med Sci Sports 14 (2004), 168-175.

[15]A.N. Sjölie, A.E. Ljunggren. The significance of high lumbar mobility and low lumbar strength for current and future low back pain in adolescents. Spine 26 (2001), 2629-2636.

[16] M.S. Sothern, M. Loftin, R.M. Suskind, J.N. Udall, U. Blecker. The health benefits of physical activity in children and adolescents: implications for chronic disease prevention. Eur J Pediatr 158 (1999), 271-274

[17] B Tancred, G. Tancred. Implementation of exercise programmes for prevention and treatment of low back pain. Physiotherapy 82 (1996), 168-173

[18]F.C. Trevelyan, S.J. Legg. Back pain in school children Where to from here? Appl Ergon 37 (2006), 45-54.

[19] K.D. Watson, A.C. Papageorgiou, G.T. Jones, S. Taylor, D.P.M. Symmons, A.J. Silman, G.J. Macfarlane. Low back pain in schoolchildren: occurence and characteristics. Pain 97 (2002), 87-92

[20]K.F Wells, E.K. Dillon. The sit-and-reach - A test of back and leg flexibility. Research Quarterly. 1952;23:115-8. 